\title{
Iodine status of New Zealand residents as assessed by urinary iodide excretion and thyroid hormones
}

\author{
BY CHRISTINE D. THOMSON ${ }^{1}$, ANDREW J. COLLS ${ }^{1}$, JOHN V. CONAGLEN ${ }^{2}$, \\ MATTHEW MACORMACK ${ }^{1}$, MARTIN STILES $^{2}$ AND JIM MANN ${ }^{1}$ \\ ${ }^{1}$ Department of Human Nutrition, University of Otago, PO Box 56, Dunedin, New Zealand \\ ${ }^{2}$ Department of Medicine, Waikato Hospital, Hamilton, New Zealand
}

(Received 6 January 1997 - Revised 28 April 1997 - Accepted 6 June 1997)

\begin{abstract}
The aims of this study were (1) to compare various measures of $I$ status, and (2) to assess urinary I and thyroid hormone status of residents of two areas of New Zealand where, before the iodization of salt, goitre was endemic due to low soil I. A total of 189 subjects (102 males, eighty-seven females) were recruited from the Dunedin Blood Transfusion Centre, and 144 (sixty-seven males, seventyseven females) from the Waikato Blood Transfusion Centre between November 1993 and June 1994. Blood was taken for thyroid hormone assays, and subjects collected a fasting overnight urine specimen, a double-voided fasting urine sample, and a complete $24 \mathrm{~h}$ specimen for iodide and creatinine analyses. Positive correlations $(P<0.0001)$ between daily iodide excretion and iodide concentrations in fasting and double-voided fasting urines, identical median values for iodide concentrations in the three samples, and similar numbers of subjects classified as at risk from I deficiency disorders according to the International Committee for the Control of Iodine Deficiency Disorders/World Health Organization categories (World Health Organization, 1994) confirmed indications from earlier studies that fasting urine samples were suitable for population studies. However $24 \mathrm{~h}$ urinary iodide excretion remains the recommended measure for individual I status. Waikato residents excreted more iodide in urine and all measures were significantly greater than for Otago residents. However median urinary iodide excretions for both areas (60 and 76 $\mu \mathrm{g} / \mathrm{d}$ for Otago and Waikato respectively) were considerably lower than those reported previously for New Zealand. Thyroid hormone concentrations were within normal ranges. Our findings suggest that I status of New Zealanders may no longer be considered adequate and may once again be approaching levels of intake associated with clinical I deficiency.
\end{abstract}

Iodine: Thyroid hormones: New Zealand

The I deficiency disorder (IDD) goitre was endemic in many parts of New Zealand before the introduction of iodized salt in the early 1940s (Hercus et al. 1925; Purves, 1974). The current level of salt fortification is $50 \mathrm{mg} / \mathrm{kg}$, but only salt for household use is fortified. More recent surveys of the I status of New Zealanders, measured by urinary iodide excretion, indicated more-than-adequate I intakes (North \& Fraser, 1965; Cooper et al. 1984; Simpson et al. 1984). This has resulted from both iodization of salt and from a substantial contribution to the I content of dairy products from the use of iodophors as equipment sanitizers in the dairy industry (Joerin \& Bowering, 1972; Sutcliffe, 1990). However, the use of iodophors is declining, resulting in a reduction in the concentration of $I$ in milk (Sutcliffe, 1990). This factor together with the recommendation to reduce salt intake (Department of Health, 1991) has raised concern that I intakes may be decreasing. In a recent pilot study, urinary iodide excretions of sixty-two residents of Dunedin, New 
Zealand were found to be considerably lower than those reported in earlier surveys suggesting that I intakes may indeed have fallen (Thomson et al. 1996).

The most reliable method for assessing I status is $24 \mathrm{~h}$ urinary iodide excretion, as urine is the predominant excretory route for I and thus reflects I intake (Gibson, 1990; World Health Organization, 1994). However $24 \mathrm{~h}$ urine samples are both inconvenient for the subject and difficult to collect accurately, and thus in population studies the iodide content is frequently measured in casual or fasting urine samples and expressed either as iodide concentration (Dunn et al. 1993) or as the iodide : creatinine ratio (Gibson, 1990). In a recent pilot study we found that fasting urine samples but not casual samples, gave a reasonable estimate of urinary iodide output on a population basis, but that $24 \mathrm{~h}$ urine samples were preferable for assessment of I status of individuals and for research purposes (Thomson et al. 1996). The double-voided fasting urine sample may represent the true fasting state as, unlike the fasting sample, it is less influenced by intake during the previous evening. Double-voided fasting samples are often used in clinical situations but to date have not been evaluated for assessing urinary I status.

The present paper reports results of a study designed (1) to compare various measures of I status, in particular the double-voided fasting urine sample, and (2) to assess urinary I and thyroid hormone status of residents of two areas of New Zealand where, before the iodization of salt, goitre was endemic due to low soil I levels.

\section{METHODS}

\section{Subjects and experimental protocol}

A total of 189 subjects (102 males, eighty-seven females) were recruited from the Dunedin Blood Transfusion Centre, and 144 (sixty-seven males, seventy-seven females) from the Waikato Blood Transfusion Centre between November 1993 and June 1994. Blood was taken for assays of serum free triiodothyronine (free $T_{3}$ ), free thyroxine (free $T_{4}$ ) and thyroid stimulating hormone (TSH). Subjects collected, into separate containers, a fasting overnight urine specimen, a double-voided fasting urine (i.e. a second fasting urine sample collected $30 \mathrm{~min}$ after the first), and a complete $24 \mathrm{~h}$ urine specimen. The collection of urine samples began $2 \mathrm{~d}$ after blood donation to allow for rehydration of body fluids. Subjects completed a questionnaire on their use of vitamin and mineral supplements and Icontaining medications. The study had the approval of the Southern Regional Health Authority Ethics Committee Otago and written consent was obtained from all participants.

\section{Sample preparation and analyses}

Urine was collected in clean bottles which had been rinsed with acid and ion-exchange water before use. Subjects were provided with clean bowls and funnels which were kept in brown paper bags along with the bottles throughout the $24 \mathrm{~h}$ collection period. A sample of each urine was stored in a clean container without preservative at $-20^{\circ}$ until analysis. Serum was stored at $-80^{\circ}$. Iodide was measured in urine using the method of Dunn et al. (1993) adapted for use on a Cobas Fara autoanalyser (F. Hoffman-La Roche \& Co., Basle, Switzerland). Duplicate samples of urine were digested in $3.5 \mathrm{M}-\mathrm{HClO}_{3}$ and iodide measured using the Sandell-Kolthoff reaction (Sandell \& Kolthoff, 1937), the reduction of cerate ion by arsenous acid and measurement of extinction at $405 \mathrm{~nm}$. Samples were digested in clean tubes at $110-115^{\circ}$ and clean marbles were placed on the top of each tube to minimize potential losses and evaporation during this step. All reagents were prepared using deionized water and all glassware and containers were soaked in detergent, washed 
with hot water, and distilled water and finally rinsed with deionized water. Our laboratory participated in two international quality control programmes (the Program Against Micronutrient Malnutrition International Quality Control Program, Center for Disease Control, Atlanta, GA, USA; and the International Committee for the Control of Iodine Deficiency Disorders (ICCIDD) Urinary Iodine Reference Laboratory, Charlottesville, VA, USA). Satisfactory agreement in iodide concentrations with other participating laboratories was obtained with these samples (C. D. Thomson and A. J. Colls, unpublished results). A pooled standard urine analysed twenty-three times over a 2-month period gave a mean concentration of 49 (SD 4.9) $\mu \mathrm{g} / \mathrm{l}(\mathrm{CV}, 10 \%)$. The detection limit was less than $5 \mu \mathrm{g} / 1$ and recoveries of added iodide of $90-100 \%$ were obtained. Urinary creatinine was measured on the Cobas Fara autoanalyser using a creatinine Uni-Kit II, creatinine calibrator and control sera (Roche Diagnostic Systems Inc). Free $T_{3}$, free $T_{4}$ and TSH were assayed by radioimmunoassay using a stratus II analyser (Dade International Inc., Miami, FL, USA) in the Endocrine Laboratory, Health Waikato.

\section{Classification of risk of iodine deficiency disorders}

The proportion of subjects classified as being at risk from IDD according to three different criteria was calculated: ranges of iodide concentration in urine (World Health Organization, 1994); iodide: creatinine ratios (National Research Council, 1989); and daily iodide excretion according to criteria adapted from Clugston \& Hetzel (1994). The latter criteria are based on epidemiological work indicating that endemic goitre is likely to appear in populations with iodide excretions less than $50 \mu \mathrm{g} / \mathrm{d}$, and endemic cretinism in those with less than $25 \mu \mathrm{g} / \mathrm{d}$.

\section{Statistical analysis}

Data processing and statistics were carried out using Microsoft Excel 4.0 (Microsoft Corporation, Redmond, WA, USA) and Statview ${ }^{\mathrm{TM}}$ SE $+{ }^{\text {Graphics }}$ v 1.03 Statistical Package (Abacus Concepts Inc., 1984 Bonita Ave, Berkeley, CA, USA). As urinary iodide and creatinine measures were not normally distributed, data analysis was carried out after logarithmic conversion. Correlation analysis by least squares regression was used to assess the strength of the relationship between the different measures of I status. Agreement among iodide concentrations and iodide : creatinine ratios in the three urine samples was assessed using difference plots (Bland \& Altman, 1986). The proportion of subjects classified as being at risk from IDD according to three different criteria was compared using the $\chi^{2}$ test. The proportions of subjects classified as being at risk from IDD according to the ICCIDD ranges of iodide concentration in urine (World Health Organization, 1994) and iodide:creatinine ratios (National Research Council, 1989) using $24 \mathrm{~h}$, fasting or double-voided fasting urine samples were also compared using the $\chi^{2}$ test. Comparisons between mean values for Otago and Waikato and between male and female subjects were made using two-tailed unpaired Student's $t$ tests. For comparison of different measures from the same subjects, the paired $t$ test was used.

\section{RESULTS}

Table 1 gives information on sex, age and BMI of the subjects. Some subjects (17\%) were taking some form of medication at the time of the study; $93 \%$ of the subjects used iodized salt and $1.7 \%$ reported using non-iodized salt. The remainder either used a salt substitute 
Table 1. Description of subjects in Otago and Waikato

\begin{tabular}{|c|c|c|c|c|c|c|}
\hline & \multicolumn{2}{|c|}{$\operatorname{Sex}(n)$} & \multicolumn{2}{|c|}{ Age (years) } & \multicolumn{2}{|c|}{ BMI $\left(\mathrm{kg} / \mathrm{m}^{2}\right)$} \\
\hline & Male & Female & Mean & (Range) & Mean & (Range) \\
\hline Otago & 102 & 87 & 42 & $(18-68)$ & 25 & $(18-37)$ \\
\hline Waikato & 67 & 77 & 43 & $(19-72)$ & 25 & $(18-34)$ \\
\hline All subjects & 169 & 164 & 43 & $(18-72)$ & 25 & $(18-37)$ \\
\hline
\end{tabular}

$(0.6 \%)$ or were unsure what was used in their household $(3.4 \%)$. Nearly half the subjects $(48 \%)$ reported never adding salt to meals at the table; $23 \%$ always and $29 \%$ sometimes; $30 \%$ never used salt in cooking; $50 \%$ always and $19 \%$ sometimes. There was no difference in salt usage between the two areas.

Two Otago subjects and one Waikato subject reported using I supplements (kelp) regularly, and a further four Otago and fifteen Waikato subjects used a vitamin-mineral preparation or medicines containing some I. Because of the marked differences in I measures between supplementers and non-supplementers (Table 2), all analyses were carried out on data for non-supplementers as well as for all subjects. Nine Otago subjects and thirteen Waikato subjects were unable to collect double-voided fasting urine samples.

\section{Iodine excretion in fasting, double-voided fasting and $24 \mathrm{~h}$ urine collections}

Table 2 summarizes median values for total daily output of iodide, iodide concentrations and the iodide: creatinine ratios in $24 \mathrm{~h}$ urines, fasting and double-voided fasting urine specimens for all Otago and Waikato residents as well as for non-supplementers in both regions. Waikato residents excreted more iodide in urine, and all measures were significantly greater than for Otago residents for all subjects and for non-supplementers $(P<0.001)$.

There was a marked difference in all measures between supplementers and nonsupplementers $(P<0.0001)$. Of those who reported using supplements, three Otago and eight Waikato residents who used supplements containing I had daily urinary excretions greater than $200 \mu \mathrm{g}$ iodide/d; two who consumed kelp regularly had excretions of 323 and $421 \mu \mathrm{g} / \mathrm{d}$.

Table 3 compares iodide excretion by males and females. Males excreted more iodide per day $(P<0.05)$, and urinary iodide concentrations were greater $(P<0.0001)$ for all male subjects and for male non-supplementers. The iodide : creatinine ratio was greater for females than for males for non-supplementers and for all subjects $(P<0.001)$ because of the greater creatinine excretion by males.

Table 4 compares the number of subjects classified as being at risk of IDD $\left(\chi^{2}=98.66\right.$, $P<0.0001)$. The proportion classified as at severe risk according to the iodide : creatinine ratio classification was greater than when the urinary iodide concentration or iodide excretion per day was measured. On the other hand the proportions classified at moderate risk according to urinary concentration criteria and iodide : creatinine ratio were greater than for daily iodide excretion. A significant number of subjects were classified as either at moderate or mild risk of IDD by all three criteria. The proportions of subjects classified as being at risk from IDD according to the ICCIDD ranges of iodide concentration in urine (World Health Organization, 1994) using $24 \mathrm{~h}$, fasting or double-voided fasting urine samples were not significantly different $\left(\chi^{2}=12.18, P=0.058\right)$, but those for 


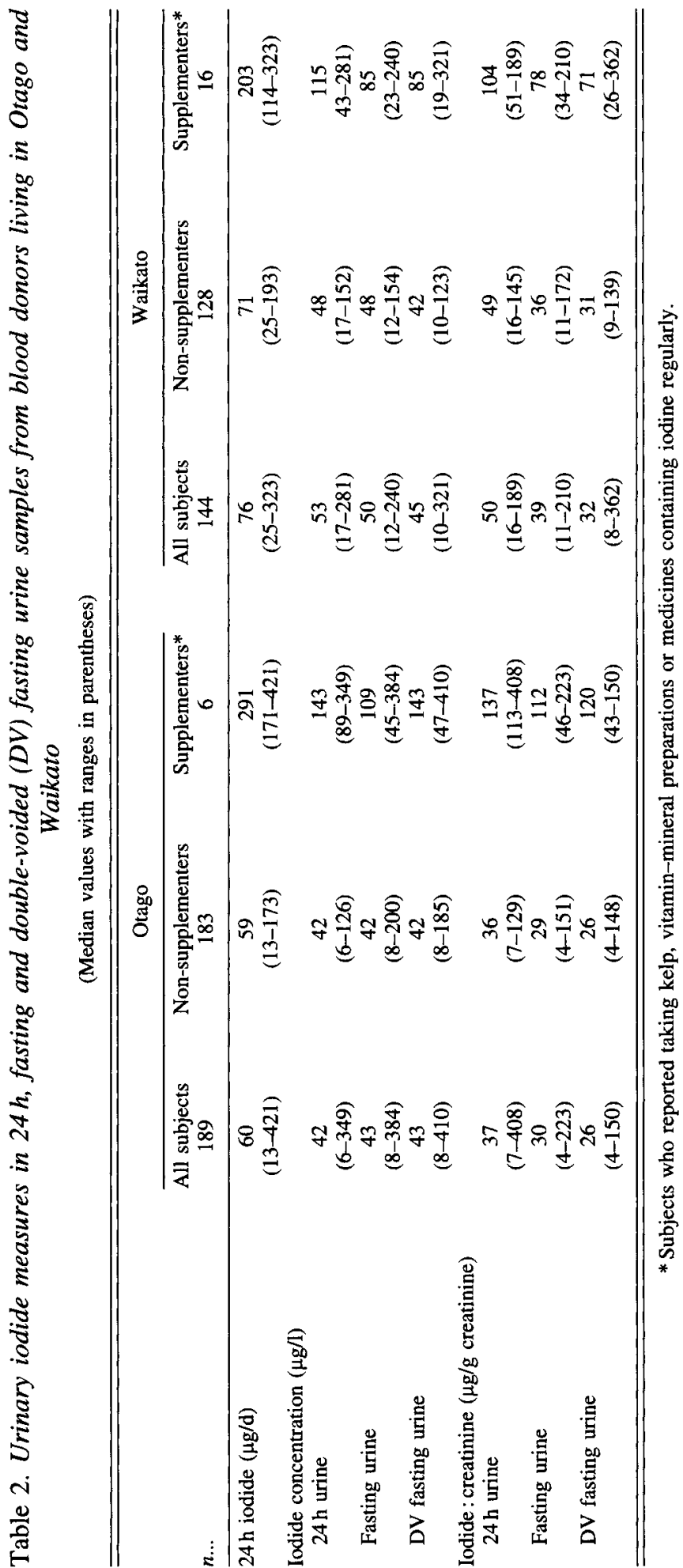


Table 3. Urinary iodide measures in $24 h$ fasting and double-voided (DV) fasting urine samples from male and female blood donors

(Median values with ranges in parentheses)

\begin{tabular}{|c|c|c|c|c|}
\hline \multirow[b]{2}{*}{$n \ldots$} & \multicolumn{2}{|c|}{ Male } & \multicolumn{2}{|c|}{ Female } \\
\hline & $\begin{array}{c}\text { All subjects } \\
169\end{array}$ & $\begin{array}{c}\text { Non-supplementers* } \\
156\end{array}$ & $\begin{array}{c}\text { All subjects } \\
164\end{array}$ & $\begin{array}{c}\text { Non-supplementers* } \\
155\end{array}$ \\
\hline $24 \mathrm{~h}$ iodide $(\mu \mathrm{g} / \mathrm{d})$ & $\begin{array}{c}73 \\
(13-323)\end{array}$ & $\begin{array}{c}70 \\
(13-193)\end{array}$ & $\begin{array}{c}62 \\
(15-421)\end{array}$ & $\begin{array}{c}59 \\
(15-165)\end{array}$ \\
\hline \multicolumn{5}{|l|}{ Iodide concentration $(\mu \mathrm{g} / \mathrm{l})$} \\
\hline 24 urine & $\begin{array}{c}49 \\
(12-281)\end{array}$ & $\begin{array}{c}45 \\
(12-152)\end{array}$ & $\begin{array}{c}44 \\
(6-350)\end{array}$ & $\begin{array}{c}42 \\
(6-123)\end{array}$ \\
\hline Fasting urine & $\begin{array}{c}51 \\
(9-240)\end{array}$ & $\begin{array}{c}49 \\
(9-200)\end{array}$ & $\begin{array}{c}42 \\
(8-384)\end{array}$ & $\begin{array}{c}40 \\
(8-130)\end{array}$ \\
\hline DV fasting urine & $\begin{array}{c}47 \\
(14-321)\end{array}$ & $\begin{array}{c}45 \\
(14-185)\end{array}$ & $\begin{array}{c}39 \\
(8-410)\end{array}$ & $\begin{array}{c}37 \\
(8-129)\end{array}$ \\
\hline \multicolumn{5}{|l|}{ Iodide : creatinine $(\mu \mathrm{g} / \mathrm{g})$} \\
\hline $24 \mathrm{~h}$ urine & $\begin{array}{c}39 \\
(7-162)\end{array}$ & $\begin{array}{c}37 \\
(7-142)\end{array}$ & $\begin{array}{c}46 \\
(10-408)\end{array}$ & $\begin{array}{c}44 \\
(10-145)\end{array}$ \\
\hline Fasting urine & $\begin{array}{c}32 \\
(7-210)\end{array}$ & $\begin{array}{c}31 \\
(7-127)\end{array}$ & $\begin{array}{c}33 \\
(4-223)\end{array}$ & $\begin{array}{c}32 \\
(4-172)\end{array}$ \\
\hline DV fasting urine & $\begin{array}{c}27 \\
(4-362)\end{array}$ & $\begin{array}{c}27 \\
(4-148)\end{array}$ & $\begin{array}{c}30 \\
(6-150)\end{array}$ & $\begin{array}{c}29 \\
(6-139)\end{array}$ \\
\hline Urinary creatinine $(\mathrm{g} / \mathrm{d})$ & $\begin{array}{c}1.91 \\
(0.6-2.97)\end{array}$ & & $\begin{array}{c}1.36 \\
(0.6-3 \cdot 68)\end{array}$ & \\
\hline
\end{tabular}

* Subjects who did not report taking regular supplements or medicines containing iodine.

iodide: creatinine ratios (National Research Council, 1989) were different $\left(\chi^{2}=47.89\right.$, $P<0.0001)$.

\section{Thyroid hormone concentrations}

Free $T_{3}$, free $T_{4}$ and $T S H$ concentrations and the free $T_{3}$ : free $T_{4}$ ratios of the two groups of blood donors are summarized in Table 5. Most thyroid hormone concentrations fell within the reference ranges (free $T_{4}, 13-25 \mathrm{pmol} / 1$; free $\mathrm{T}_{3}, 2.2-6.8 \mathrm{pmol} / 1$; TSH, $0.3-3.0 \mathrm{mU} / \mathrm{l}$ ) and there was no relationship with $24 \mathrm{~h}$ iodide excretion. Differences were observed

Table 4. Proportion of subjects at risk from iodine deficiency disorders (IDD) according to three different classifications*

\begin{tabular}{|c|c|c|c|c|c|c|}
\hline \multirow[b]{2}{*}{ Risk of IDD } & \multicolumn{2}{|c|}{$\begin{array}{l}\text { Urinary iodide concentration } \dagger \\
(\mu \mathrm{g} / \mathrm{l})\end{array}$} & \multicolumn{2}{|c|}{$\begin{array}{l}\text { Urinary iodide : creatinine } \\
\text { ratio }{ }^{\dagger}(\mu \mathrm{g} / \mathrm{g})\end{array}$} & \multicolumn{2}{|c|}{$\begin{array}{c}24 \mathrm{~h} \text { iodide excretion } \\
(\mu \mathrm{g} / \mathrm{d})\end{array}$} \\
\hline & Criteriaf & $n$ & Criteria§ & $n$ & Criteria\| & $n$ \\
\hline Severe & $<20$ & $23(7 \%)$ & $\leq 25$ & $56(18 \%)$ & $<25$ & $16(5 \%)$ \\
\hline Moderate & $20-49$ & $157(50 \%)$ & $2 \overline{5}-50$ & $141(45 \%)$ & $25-50$ & $81(26 \%)$ \\
\hline Mild & $50-100$ & $110(35 \%)$ & $50-100$ & $96(30 \%)$ & $50-100$ & $156(50 \%)$ \\
\hline None & $>100$ & $24(8 \%)$ & $>100$ & $21(7 \%)$ & $>100$ & $61(19 \%)$ \\
\hline
\end{tabular}

* Only subjects for whom all three values were available are included. Significant difference among the three classifications $\chi^{2}=98.66, P<0.0001$.

$+24 \mathrm{~h}$ measures.

$\ddagger$ ICCIDD/WHO (World Health Organization, 1994).

$\S$ National Research Council (1989).

|| Criteria adapted from Clugston \& Hetzel (1994). 
Table 5. Thyroid hormone concentrations of blood donors living in Otago and Waikato (Median values with ranges in parentheses)

\begin{tabular}{|c|c|c|c|c|}
\hline \multirow[b]{2}{*}{$n \ldots$} & \multicolumn{2}{|c|}{ Otago } & \multicolumn{2}{|c|}{ Waikato } \\
\hline & $\begin{array}{c}\text { Male } \\
102\end{array}$ & $\begin{array}{c}\text { Female } \\
87\end{array}$ & $\begin{array}{c}\text { Male } \\
67\end{array}$ & $\begin{array}{c}\text { Female } \\
77\end{array}$ \\
\hline Free $T_{4}(\mathrm{pmol} / 1)$ & $\begin{array}{c}17 \\
(12-23)\end{array}$ & $\begin{array}{c}16 \\
(11-31)\end{array}$ & $\begin{array}{c}18 \\
(13-28)\end{array}$ & $\begin{array}{c}17 \\
(11-24)\end{array}$ \\
\hline Free $T_{3}(\mathrm{pmol} / \mathrm{l})$ & $\begin{array}{c}4.9 \\
(4.0-6 \cdot 9)\end{array}$ & $\begin{array}{c}4 \cdot 7 \\
(3 \cdot 8-7 \cdot 6)\end{array}$ & $\begin{array}{c}4 \cdot 8 \\
(3 \cdot 3-7 \cdot 3)\end{array}$ & $\begin{array}{c}4.7 \\
(2 \cdot 7-7 \cdot 8)\end{array}$ \\
\hline Free $T_{3}:$ free $T_{4}$ & $\begin{array}{c}0.29 \\
(0.18-0.45)\end{array}$ & $\begin{array}{c}0.30 \\
(0.15-0.45)\end{array}$ & $\begin{array}{c}0.26 \\
(0.17-0.43)\end{array}$ & $\begin{array}{c}0.28 \\
(0.12-0.50)\end{array}$ \\
\hline TSH (mU/l) & $\begin{array}{c}0.9 \\
(0.1-2 \cdot 8)\end{array}$ & $\begin{array}{c}0.9 \\
(0.1-3.7)\end{array}$ & $\begin{array}{c}1.3 \\
(0.4-4.7)\end{array}$ & $\begin{array}{c}1.5 \\
(0.2-7.9)\end{array}$ \\
\hline
\end{tabular}

$\mathrm{T}_{3}$, triiodothyronine; $\mathrm{T}_{4}$, thyroxine; $\mathrm{TSH}$, thyroid stimulating hormone.

between males and females for free $\mathrm{T}_{4}(P<0.05)$ and free $\mathrm{T}_{3}(P<0.005)$ and between Otago and Waikato subjects for free $\mathrm{T}_{4}$ and TSH $(P<0 \cdot 0005)$.

\section{Correlation coefficients for urinary iodide measures}

Table 6 summarizes correlation coefficients for relationships among fasting, double-voided fasting and $24 \mathrm{~h}$ urinary iodide measures for all subjects. The correlation coefficients for the relationships between fasting and double-voided fasting urines were 0.695 for iodide concentration and 0.687 for iodide : creatinine ratio $(P<0.0001)$. Difference plots (Bland \& Altman, 1986) indicated unsatisfactory agreement between measures of iodide concentration and iodide : creatinine ratios between urine samples and the scatter of the differences increased as urinary iodide increased.

\section{Effect of age on urinary iodide and creatinine measures}

Correlation coefficients for relationships between age and urinary iodide measures are summarized in Table 7. Daily iodide excretion increased with age in female $(P=0.005)$

Table 6. Correlation coefficients (r)* for relationships among $24 \mathrm{~h}$, fasting and double-voided $(D V)$ fasting urinary iodide measures

\begin{tabular}{|c|c|c|c|}
\hline & \multicolumn{3}{|c|}{$24 \mathrm{~h}$ iodide excretion } \\
\hline & $\begin{array}{c}24 \mathrm{~h} \text { iodide } \\
(\mu \mathrm{g} / \mathrm{d})\end{array}$ & $\begin{array}{l}\text { Iodide concentration } \\
(\mu \mathrm{g} / \mathrm{l})\end{array}$ & $\begin{array}{c}\text { Iodide : creatinine } \\
\qquad(\mu \mathrm{g} / \mathrm{g})\end{array}$ \\
\hline \multicolumn{4}{|l|}{ Iodide concentration $(\mu \mathrm{g} / \mathrm{h})$} \\
\hline $24 \mathrm{~h}$ & 0.697 & & \\
\hline Fasting & 0.492 & 0.593 & 0.394 \\
\hline DV fasting & 0.475 & 0.612 & 0.413 \\
\hline \multicolumn{4}{|l|}{ Iodide : creatinine $(\mu \mathrm{g} / \mathrm{g})$} \\
\hline $24 \mathrm{~h}$ & 0.833 & 0.556 & \\
\hline Fasting & 0.587 & 0.359 & 0.687 \\
\hline DV fasting & 0.597 & 0.382 & 0.692 \\
\hline Urinary creatinine $(\mu \mathrm{g} / \mathrm{d})$ & 0.324 & 0.253 & -0.243 \\
\hline
\end{tabular}

$* P<0.0001$ for all correlation coefficients. 
Table 7. Correlation coefficients (r) for $24 h$ urinary iodide and creatinine measures with age

\begin{tabular}{lccc}
\hline & All subjects & Male & Female \\
\hline $24 \mathrm{~h}$ iodide $(\mu \mathrm{g} / \mathrm{d})$ & 0.222 & $\mathrm{NS}$ & $0 \cdot 280^{* * *}$ \\
Iodide concentration $(\mu \mathrm{g} / \mathrm{l})$ & $\mathrm{NS}$ & $\mathrm{NS}$ & $\mathrm{NS}$ \\
Iodide $:$ creatinine $(\mu \mathrm{g} / \mathrm{g})$ & 0.228 & $0.163^{*}$ & $0 \cdot 370$ \\
$24 \mathrm{~h}$ creatinine $(\mathrm{g} / \mathrm{d})$ & $\mathrm{NS}$ & $\mathrm{NS}$ & $\mathrm{NS}$ \\
Creatinine concentration $(\mathrm{mmol} / \mathrm{l})$ & $-0.154^{* *}$ & $\mathrm{NS}$ & -0.373 \\
Urine volume $(\mathrm{ml})$ & $0 \cdot 183^{* * *}$ & $\mathrm{NS}$ & 0.322 \\
\hline
\end{tabular}

$P<0.0001$ for all correlation coefficients except: *P<0.05, **P<0.01, *** $P<0.001$.

but not male subjects, while $24 \mathrm{~h}$ iodide concentration decreased $(P<0.01)$. Iodide : creatinine ratios increased in all three samples for females $(P<0.001)$ and for males in $24 \mathrm{~h}$ and fasting urines $(P<0.05)$. These relationships in females may be due in part to the decrease in urinary creatinine concentration $(P<0.001)$ and an increase in urine volume $(P<0.0001)$.

\section{DISCUSSION}

\section{Urinary measures of iodine status}

Collection of complete $24 \mathrm{~h}$ urine specimens is difficult and inconvenient for subjects, and the ICCIDD recommends the use of median values for iodide concentration in casual urine samples of a selected population group. One aim of this study was to evaluate the fasting and double-voided fasting urine samples for assessing urinary iodine status either for the individual or for population groups. This was achieved by measuring the strength of the relationship between the variables to determine whether one measure would give an indication of the other in terms of high, medium or low I status. This study confirms the positive relationship between total $24 \mathrm{~h}$ urinary iodide excretion and iodide concentrations in fasting urine samples demonstrated by us in a previous pilot study (Thomson et al. 1996), and by other groups (Vought et al. 1963; Konno et al. 1993; Remer \& Manz, 1994). However, the correlations were weak, and distance plots indicated that fasting urines are not adequate for predicting individual daily I excretion. Thus $24 \mathrm{~h}$ urine samples remain the most suitable and recommended measure, especially for research purposes (Thomson et al. 1996).

However, median values for iodide concentrations of the three urine samples were almost identical for the Otago subjects and similar for the Waikato subjects, and the proportion of individuals classified into risk categories for IDD by the ICCIDD/World Health Organization criteria of iodide concentration was similar for each of the three urine samples. These observations confirm our previous results (Thomson et al. 1996) and those of others (Vought et al. 1963; Konno et al. 1993; Remer \& Manz, 1994) which indicated that measurement of iodide in fasting urines is useful in assessing the I status in population groups in terms of high, medium and low I status in order to assess risk of IDD, and this conclusion is supported by the significant correlations of fasting iodide excretion with $24 \mathrm{~h}$ iodide excretion and $24 \mathrm{~h}$ concentration.

On the other hand, although correlations for iodide : creatinine ratios with $24 \mathrm{~h}$ iodide excretion were somewhat better than for iodide concentration, the median values for iodine : creatinine ratios in fasting and, in particular, double-voided fasting urines were less than for $24 \mathrm{~h}$ urines, and median values differed significantly among the three samples 
$(P<0.0001)$ despite similar iodide concentrations. As a result, $24 \mathrm{~h}$ iodide excretions estimated from iodide:creatinine ratios in fasting and double-voided fasting urines (iodide : creatinine ratio $\times 24 \mathrm{~h}$ creatinine) were less than the analysed value $(P<0.0001)$ and would thus overestimate the proportion of subjects classified as at risk of IDD according to this criterion. Furthermore the $24 \mathrm{~h}$ iodide:creatinine ratio showed a significant negative correlation with creatinine excretion and iodide:creatinine ratios increased with age for males and females, whereas total $24 \mathrm{~h}$ iodide excretion increased to a lesser extent with age and only in females. This was due to a decrease in creatinine excretion with age, although the decrease was significant only for urinary creatinine concentration. These latter observations have been reported by others (Konno et al. 1993; Furnée et al. 1994; Remer \& Manz, 1994) who concluded that creatinine should not be used as an adjustment factor for assessment of I status. In addition, low creatinine excretion which may occur in areas of malnutrition may mask I deficiency, while high creatinine excretion in a well-nourished population such as in New Zealand will overestimate the proportion of individuals classified as at risk from IDD. In our population the proportion of subjects classified as at severe risk from IDD according to the iodide : creatinine criterion was greater than that obtained when using the criteria for iodide concentration and total $24 \mathrm{~h}$ excretion (Table 4). Therefore the iodide : creatinine ratio is not a suitable index for assessing I status.

The reason for the somewhat lower values for double-voided urine samples is not clear, other than the possibility that values were influenced by the number of subjects who were unable to collect these samples so soon after the fasting urine $(n=22)$, and by others whose urine volume of this sample was extremely small. For this reason the fasting urine sample may be more reliable. Furthermore there was little difference between fasting and double-voided fasting urines (for both iodide concentration and iodide : creatinine ratios) in relationship to $24 \mathrm{~h}$ urinary measures.

\section{Iodine status of New Zealand residents}

Urinary iodide excretions of both Otago and Waikato residents were considerably lower than those reported previously for New Zealanders (North \& Fraser, 1965; Cooper et al. 1984; Simpson et al. 1984) (Table 8), and also considerably lower than the recommended dietary intake of I of $150 \mu \mathrm{g} / \mathrm{d}$ (Truswell et al. 1990). They confirm low values found in pilot studies carried out in our laboratory (Thomson et al. 1995, 1996). Analytical techniques could account for low values but our laboratory has performed consistently well in comparison with other laboratories in international quality control programmes.

The present results suggest that in at least two regions of New Zealand there has been a decrease in I intake over the last decade. Median iodide concentrations fell within the range of $20-49 \mu \mathrm{g} / \mathrm{l}$ of moderate stage of risk of IDD (Dunn et al. 1993) and twenty-three (7\%) of those subjects had levels $<20 \mu \mathrm{g} / 1$ within the range for severe IDD, of which nineteen were from Otago and four from Waikato. A significant number of subjects were classified as either at moderate or mild risk of IDD by all three criteria. A further $157(50 \%)$ (ninetyseven from Otago and sixty from Waikato) had levels between 20 and $49 \mu \mathrm{g} / \mathrm{d}$. The median total $24 \mathrm{~h}$ iodide excretion was $60 \mu \mathrm{g} / \mathrm{d}$ for Otago blood donors with the majority $(79 \%)$ less than $100 \mu \mathrm{g} / \mathrm{d}$ and $30 \%$ less than $50 \mu \mathrm{g} / \mathrm{d}$, which is considered to be a marginal I intake. Iodide excretion values for Waikato residents were higher with $71 \%$ below $100 \mu \mathrm{g} /$ $\mathrm{d}$ and $23 \%$ below $50 \mu \mathrm{g} / \mathrm{d}$.

Thyroid hormone concentrations were within normal ranges and thus the physiological significance of the low iodide excretions is unclear. The ability of the TSH assay to detect I 
Table 8. Urinary iodide excretion by New Zealand residents

(Mean values and standard deviations)

\begin{tabular}{|c|c|c|c|c|c|c|}
\hline \multirow[b]{3}{*}{ Location } & \multirow[b]{3}{*}{ Year } & \multicolumn{4}{|c|}{ Urinary iodide $(\mu \mathrm{g} / \mathrm{d})$} & \multirow[b]{3}{*}{ Reference } \\
\hline & & \multicolumn{2}{|c|}{ Male } & \multicolumn{2}{|c|}{ Female } & \\
\hline & & Mean & $\mathrm{SD}$ & Mean & $\mathrm{SD}$ & \\
\hline Cromwell (goitrous) & 1936 & \multicolumn{4}{|c|}{25} & Purves (1974) \\
\hline New Plymouth (moderately goitrous) & 1936 & \multicolumn{4}{|c|}{57} & Purves (1974) \\
\hline Wellington & 1965 & 248 & 95 & 196 & 91 & North \& Fraser (1965) \\
\hline Auckland & 1980 & & & 300 & 102 & Cooper et al. (1984) \\
\hline Milton, Otago & 1982 & 267 & 114 & 216 & 76 & Simpson et al. (1984) \\
\hline Wellington & 1991 & & & 174 & 56 & Ford et al. (1991) \\
\hline Otago & 1992 & 64 & 30 & 55 & 27 & Thomson et al. (1996) \\
\hline Otago* & 1993 & 68 & 34 & 59 & 27 & Present study \\
\hline Waikato* & 1993 & 85 & 35 & 68 & 27 & Present study \\
\hline
\end{tabular}

* Non-supplementers.

deficiency has not been clearly quantified. For example elevated levels of TSH of about 20-25 mU/1 serve as a cut-off point for identifying congenital hypothyroidism, however I deficiency may be associated with TSH levels only slightly above normal, at $5 \mathrm{mU} / \mathrm{l}$ (World Health Organization, 1994). Other workers found normal levels of $\mathrm{T}_{3}, \mathrm{~T}_{4}$ and $\mathrm{TSH}$ in mild I deficiency when urinary iodide excretion was low (Bourdoux, 1993), and the reliability of the TSH assay as an indicator of I status in adults older than 30 years has been questioned (World Health Organization, 1994). Similarly free $T_{4}$ and free $T_{3}$ may not be useful for assessing I deficiency as there is a large overlap of values for the euthyroid and hypothyroid populations (Nagayama et al. 1993), and these values do not change in response to dietary I within normal limits (Bastomsky et al. 1978; Paul et al. 1988). These assays are the most appropriate diagnostic test for hypothyroidism, but may not be true indicators of I status in adults. An alternative measure is thyroglobulin which has been reported to change more rapidly after alteration of I intake than the TSH assay (World Health Organization, 1994; Mißler et al. 1994).

The results of the present study suggest that I status of some New Zealand residents may no longer be considered adequate. Blood donors were selected because of the ease of recruiting these subjects and because they are more likely to collect accurate $24 \mathrm{~h}$ urine samples. Little information is available about the nature of New Zealand blood donors, however in other countries donors are reported to be more likely of Caucasian origin, middle-aged, well-educated and financially secure, and are selected on the basis of their good health and motivation (Oswalt \& Gordon, 1993; Thompson, 1993; Royse \& Doochin, 1995). It is conceivable, therefore, that this group would follow the nutritional recommendation to reduce salt intake, and this might have influenced the results of this study. The majority of New Zealanders use iodized salt ( $93 \%$ in the present study), although non-iodized salt is available at a slightly lower price. However a significant proportion of the subjects $(48 \%)$ reported never adding salt at the meal and $30 \%$ never used salt in cooking. No equivalent up-to-date information is available for New Zealanders other than blood donors, nor is there information on current salt intake. On the other hand, blood donors being of higher socio-economic status, might be more likely to eat fish which is relatively expensive in New Zealand. However the low level of I excretion suggests that further surveillance is necessary, particularly in vulnerable groups such as pregnant women 
and children. The median iodide excretions of $59 \mu \mathrm{g} / \mathrm{d}$ for Otago and $71 \mu \mathrm{g} / \mathrm{d}$ for Waikato non-supplementers suggest median intakes of I (assuming 75-90\% excreted in urine) of $65-95 \mu \mathrm{g} / \mathrm{d}$, which are appreciably lower than the Australian recommended nutrient intake of $150 \mu \mathrm{g} / \mathrm{d}$ for adults (Truswell et al. 1990) and the United Kingdom reference nutrient intake of $140 \mu \mathrm{g} / \mathrm{d}$ (Department of Health, 1991).

The iodine intakes of New Zealanders may have dropped, and may continue to do so, because of a reduced salt usage in cooking due to the introduction of microwave cooking, a positive response to health guidelines, and the phasing out of iodophor cleansing detergents in the dairy industry. Furthermore people born during the last two decades may have little understanding of the consequences of I deficiency and the need for dietary I. The reasons for, and the clinical significance of the decreasing I status are being investigated. It is possible that New Zealanders may once again be approaching levels of intake associated with clinical I deficiency. Continued surveillance is essential.

We wish to thank Mrs Margaret Waldron, Dr Jim Faed, Mr Les Milligan and the Dunedin and Waikato Blood Transfusion Centres for their assistance, Mr John Speed, Endocrine Laboratory Waikato Hospital for thyroid hormone assays, and the subjects for their participation. The study was funded by an Otago Medical Research Foundation Laurenson Award and the Ministry of Health.

\section{REFERENCES}

Bastomsky, C. H., Banovac, K., Skreb, F. \& Sekso, M. (1978). Similar serum concentrations of thyroid hormones in two geographically separate populations on disparate iodine intake. Hormone and Metabolic Research 11, 301-304.

Bland, J. M. \& Altman, D. G. (1986). Statistical methods for assessing agreement between two methods of clinical measurement. Lancet $\mathbf{i}, 307-310$.

Bourdoux, P. P. (1993). Biochemical evaluation of iodine status. In Iodine Deficiency in Europe. A Continuing Concern, pp. 119-125 [F. Delange, J. T. Dunn and D. Glinoer, editors]. New York: Plenum Press.

Clugston, G. A. \& Hetzel, B. S. (1994). Iodine. In Modern Nutrition in Health and Disease, vol. 1, pp. 252-263 [M. E. Shils, J. A. Olson and M. Shike, editors]. Malver, PA: Lea \& Febiger.

Cooper, G. J. S., Croxson, M. S. \& Ibbertson, H. K. (1984). Iodine intake in an urban environment: a study of urine iodide excretion in Auckland. New Zealand Medical Journal 97, 142-145.

Department of Health (1991). Iodine. In Dietary Reference Values for Food Energy and Nutrients for the United Kingdom. Report on Health and Social Subjects no. 41, pp. 183-186. London: H. M. Stationery Office.

Dunn, J. T., Crutchfield, H. E., Gutekunst, R. \& Dunn, A. D. (1993). Methods for Measuring Iodine in Urine. The Netherlands: ICCIDD/UNICEF/WHO.

Ford, H. C., Johnson, L. A., Feek, C. M. \& Newton, J. D. (1991). Iodine intake and the seasonal incidence of thyrotoxicosis in New Zealand. Clinical Endocrinology 34, 179-181.

Furnée, C. A., van der Haar, F., West, C. E. \& Hautvast, J. G. A. J. (1994). A critical appraisal of goiter assessment and the ratio of urinary iodine to creatinine for evaluating iodine status. American Journal of Clinical Nutrition 59, 1415-1417.

Gibson, R. S. (1990). Principles of Nutritional Assessment. New York: Oxford University Press.

Hercus, C. E., Benson, W. N. \& Carter, C. L. (1925). Endemic goitre in New Zealand and its relation to the soiliodine. Journal of Hygiene 24, 321-402.

Joerin, M. M. \& Bowering, A. (1972). The total iodine content of cow's milk. New Zealand Journal of Dairy Science and Technology 7, 155-158.

Konno, N., Miura, K., Kumagai, M. \& Murakami, S. (1993). Clinical evaluation of the iodide/creatinine ratio of casual urine samples as an index of daily iodide excretion in a population study. Endocrine Journal 40, 163169.

Mißler, U., Gutekunst, R. \& Wood, W. G. (1994). Thyroglobulin is a more sensitive indicator of iodine deficiency than thyrotropin: development and evaluation of dry blood spot assays for thyrotropin and thyroglobulin in iodine-deficient geographical areas. European Journal of Clinical Chemistry and Clinical Biochemistry 32, 137-143.

Nagayama, I., Yamamoto, K., Saito, K., Kuzuya, T. \& Saito, T. (1993). Subject-based reference values in thyroid function tests. Endocrine Journal 40, 557-562. 
National Research Council (1989). Recommended Dietary Allowances, 10th ed. Washington, DC: National Academy Press.

North, K. A. K. \& Fraser, S. (1965). Iodine intake as revealed by urinary iodide excretion. New Zealand Medical Journal 65, 512-513.

Oswalt, R. \& Gordon, J. (1993). Blood donor motivation: a survey of minority college students. Psychological Reports 72, 785-786.

Paul, T., Meyers, B., Witorsch, R. J., Pino, S., Chipkin, S., Inbar, S. H. \& Braverman, L. E. (1988). The effect of small increases in dietary iodine on thyroid function in euthyroid subjects. Metabolism 37, 121-124.

Purves, H. D. (1974). The aetiology and prophylaxis of endemic goitre and cretinism. The New Zealand experience. New Zealand Medical Journal 80, 477-479.

Remer, T. \& Manz, F. (1994). The inadequacy of the urinary iodine-creatinine ratio for the assessment of iodine status during infancy, childhood and adolescence. Journal of Trace Elements and Electrolytes in Health and Disease 8, 217-219.

Royse, D. \& Doochin, K. E. (1995). Multi-gallon blood donors: who are they? Transfusion 35, 826-831.

Sandell, E. B. \& Kolthoff, I. M. (1937). Micro determination of iodine by a catalytic method. Mikrochimica Acta 1, 9-25.

Simpson, F. O., Thaler, B. I., Paulin, J. M., Phelan, E. L. \& Cooper, G. J. S. (1984). Iodide excretion in a saltrestriction trial. New Zealand Medical Journal 97, 890-893.

Sutcliffe, E. (1990). Iodine in New Zealand milk. Food Technology in New Zealand July, 32-38.

Thompson, W. W. (1993). Blood donation behaviour of Hispanics in the Lower Rio Grande Valley. Transfusion 33, 333-335.

Thomson, C. D., Packer, M. A., Duffield, A. J., O’Donaghue, K. L., Butler, J. A. \& Whanger, P. D. (1995). Urinary iodine during pregnancy and lactation. Proceedings of the Nutrition Society of New Zealand 20,140142.

Thomson, C. D., Smith, T. E., Butler, K. A. \& Packer, M. A. (1996). An evaluation of urinary measures of iodine and selenium status. Journal of Trace Elements in Medicine and Biology 10, 214-222.

Truswell, A. S., Dreosti, I. E., English, R. M., Rutishauser, I. H. E. \& Palmer, N. (1990). Recommended Nutrient Intakes. Australian Papers. Sydney: Australian Professional Publications.

Vought, R. L., London, W. T., Lutwak, L. \& Dublin, T. D. (1963). Reliability of estimates of serum inorganic iodine and daily fecal and urinary excretion from single casual specimens. Journal of Clinical Endocrinology and Metabolism 23, 1218-1228.

World Health Organization (1994). Indicators for Assessing Iodine Deficiency Disorders and their Control Through Salt Iodization. Geneva: World Health Organization. 